\title{
SIMBOL DAN MAKNA SIRIH PINANG PADA SUKU ATONI PAH METO DI TIMOR TENGAH UTARA
}

\author{
Erna Suminar ${ }^{1}$
}

\begin{abstract}
This paper investigate social interaction, the meaning of messages and, human actions are activities based on certain symbols. This research focuses on the Sirih pinang tradition of the people of the Atoni Pah Meto tribe. Sirih Pinang has a role in the fundamental cultural symbols in the life of social courtesy and social interaction. Using the Symbolic Interaction Theory Herbert Blumer (1986), this study explains the symbolic function and meaning of Sirih Pinang which will be useful for everyone in establishing social, economic, educational and, political relations with the Atoni Pah Meto tribe, also for the Atoni Pah Meto community. This study uses a qualitative method with participant observation. Three Indigenous Elders who have in-depth knowledge of this tradition were critical informants in the study. Participant observations were carried out in the field by living and living with the Atoni Pah Meto tribe during the survey in the Kefetoran Aplal North Central Timor Regency, East Nusa Tenggara Province. The results of this study indicate relationship between Sirih Pinang symbol and the local religious beliefs of ancestral heritage. In ritual communication to honour the spirits of sirih pinang is a symbol that has ethical values and meaning. Sirih Pinang is included in unifying tribal members and in breaking up as a practice of various forms of communication that has the value and meaning of family and friendship. Furthermore, humans modify the meaning, the result of developing social interaction. Sirih Pinang is used as a tool for negotiation, lobbying and enters the realm of political communication and then experiences a shift in meaning.
\end{abstract}

Keywords: Symbolic Interaction Theory, Intracultural Communication, Atoni Pah Meto Tribe, Indonesian Culture, Sirih Pinang.

\begin{abstract}
Abstrak
Makalah ini untuk menyelidiki bagaimana interaksi sosial, makna pesan dan, tindakan manusia berdasarkan simbol-simbol tertentu. Penelitian berfokus pada tradisi pinang Sirih masyarakat suku Atoni Pah Meto. Sirih Pinang memiliki peran dalam simbol-simbol budaya mendasar dalam kehidupan kesopanan sosial dan interaksi sosial. Menggunakan Teori Interaksi Simbolik Herbert Blumer (1986), penelitian ini menjelaskan fungsi simbol dan makna Sirih Pinang yang berguna bagi semua orang dalam membangun hubungan sosial, ekonomi, pendidikan dan politik dengan suku Atoni Pah Meto. Penelitian ini menggunakan metode kualitatif dengan observasi partisipan. Tiga Penatua Adat yang memiliki pengetahuan mendalam tentang tradisi ini adalah informan kunci dalam penelitian ini. Pengamatan peserta dilakukan di lapangan dengan tinggal dan hidup dengan suku Atoni Pah Meto selama survei di wilayah Kefetoran Aplal Kabupaten Timor Tengah Utara, Provinsi Nusa Tenggara Timur. Hasil penelitian ini menunjukkan bahwa ada hubungan antara simbol Sirih Pinang dan kepercayaan agama lokal warisan leluhur. Dalam komunikasi ritual untuk menghormati arwah sirih pinang adalah simbol yang memiliki nilai dan makna etis. Sirih Pinang adalah simbol pemersatu anggota suku dan praktik berbagai bentuk komunikasi yang memiliki nilai dan makna dalam keluarga dan persahabatan. Selanjutnya, manusia memodifikasi maknanya pada pengembangan interaksi sosial. Sirih Pinang digunakan sebagai alat untuk negosiasi, lobi dan memasuki ranah komunikasi politik serta kemudian mengalami pergeseran makna.
\end{abstract}

\footnotetext{
${ }^{1}$ Alamat kini : Universitas Kebangsaan Republik Indonesia, Jl Terusan Halimun 37, Bandung 40263

Korespondensi : ernasuminarix@gmail.com
} 
Kata kunci: Teori Interaksi Simbolik, Komunikasi Intrakultural, Suku Atoni Pah Meto, Budaya Indonesia, Sirih Pinang.

\section{Pendahuluan}

Manusia adalah makhluk makna, yang hidup dalam lingkungan alamiah dan simbolik. Objek tidak tidak memiliki makna sendiri, melainkan karena mendapatkan artinya dari manusia. (Aksan, Kisac, Aydın, \& Demirbuken, 2009). Manusia menggunakan simbol dalam komunikasi agar pesan dapat dipahami oleh penerima pesan. Kemampuan untuk berpikir dengan menggunakan simbol adalah pencapaian luar biasa dalam perkembangan kognitif individu, dan yang berinteraksi dengan pembelajaran budaya (White, Carlson \& David Zelazo, 2019). Perbedaan latar belakang budaya membuat sebuah simbol memiliki makna yang berbeda. Interpretasi terhadap sebuah simbol berkaitan dengan konteks, subkonteks dan sejarah simbol tersebut dalam sebuah lingkungan budaya.

Dalam tradisi masyarakat tertentu, sirih (piper betle) dan pinang (areca catechu) tidak lagi dipandang sebagai tanaman sesuai dengan kenyataannya, melainkan dijadikan simbol untuk diberikan makna. Mengunyah sirih pinang menjadi tradisi banyak suku di Indonesia dan di beberapa negara Asia seperti Vietnam, Laos, Philipina, Thailand, Myanmar dan negara lainnya. Setiap suku di Indonesia memiliki kepercayaan dan maknanya sendiri dalam praktik tradisi ini dan mengembangkan filosofinya yang bersumber kepada kearifan lokal budaya mereka. Namun di Pulau Jawa, khususnya pada Suku Sunda dan Suku Jawa, tradisi menguyah sirih pinang sudah hampir punah. Praktik mengunyah sirih pinang di Pulau Jawa dilakukan oleh orang-orang berusia lanjut dan tinggal di pedalaman, dan itu juga sudah sangat langka.

Suku Atoni Pah Meto adalah salah satu suku di Timor Barat Provinsi Nusa Tenggara Timur memiliki tradisi yang sangat kuat dalam praktik mengunyah sirih pinang. Suku Atoni Pah Meto mendiami wilayah sebagian Timor Barat, Indonesia dan Distrik Oecusse, Timor Leste. Mereka menyebut diri Atoni Pah Meto yang berarti orang dari tanah kering. Ini menyiratkan cara hidup mereka tidak berkaitan dengan pantai atau laut (Nordholt, 1981: 1). Dalam Sensus Penduduk pada tahun 2009, populasi dan penutur bahasa Atoni Pah Meto (Bahasa Meto) diperkirakan sejumlah 700.000 orang dengan beberapa dialek.

Secara umum dalam praktik budaya, Suku Atoni Pah Meto mengunyah sirih dan buahnya dicampur bersama pinang, tembakau dan kapur. Namun yang paling umum dalam tradisi Suku Atoni Pah Meto adalah mencampur sirih, pinang dan kapur. Campuran bahan-bahan tersebut kemudian dikunyah dengan lembut, terkadang menghabiskan waktu berjam-jam. Penggunaan sirih pinang menghasilkan perubahan warna pada rongga mulut dan gigi. Ketika sirih dikunyah, menghasilkan efek psikoaktif dan kolinergik ringan. Ada banyak produksi air liur berwarna merah darah yang dapat menodai struktur mulut. Setelah bertahun-tahun mengunyah, gigi bisa menjadi merah-coklat hingga hampir hitam (Norton, 1998).

Dalam budaya Suku Atoni Pah Meto tradisi mengunyah sirih pinang disebut "mamat". Peranan sirih pinang sebagai simbol budaya sangat mendasar dalam kehidupan masyarakat adat. Selain simbol budaya, mengunyah sirih pinang dilakukan masyarakat Suku Atoni Pah Meto dilakukan sebagai kebiasaan sebagaimana minum kopi, merokok, minum teh atau makan. Dalam tingkat yang sudah sangat kecanduan mengunyah sirih pinang, mereka akan memprioritaskan mengunyah sirih pinang sebelum mengkonsumsi makanan lainnya.

Sirih pinang adalah pembuka komunikasi, dan sopan santun budaya dalam Suku Atoni Pah Meto. Seluruh pertemuan tidak memiliki makna tanpa sirih pinang. Rasa malu dan perasaan bersalah akan dirasakan jika tidak tersedia sirih pinang dalam rumah, terutama jika ada tamu atau keluarga datang berkunjung. Selain sebagai pembuka komunikasi, sirih pinang menjadi bahasa simbol dalam setiap upacara-upacara adat dan juga memiliki sebagai simbol dalam komunikasi religius. Sirih pinang memiliki peranan sebagai alat bantu dalam komunikasi untuk mengatasi 
konflik (memecah ketegangan dan kecemasan), juga komunikasi politik. Tanpa sirih pinang, komunikasi dengan pendekatan kultural dalam Suku Atoni Pah Meto akan mengalami kegagalan, ketersinggungan dan penolakan. Situasi yang tidak nyaman akan dihadapi para pemberi pesan dan penerima pesan dalam komunikasi saat mengabaikan ataupun tidak memahami simbol sirih pinang dalam komunikasi dengan pendekatan kultural pada Suku Atoni Pah Meto. Nilai sirih pinang sebagai simbol komunikasi perlu diketahui setiap orang atau komunitas yang akan menjalin kontak sosial, budaya, ekonomi, politik dan keamanan dengan suku ini.

Tradisi mengunyah sirih pinang terus berlangsung hingga saat ini, dan melekat dalam kehidupan Suku Atoni Pah Meto. Studi mengenai tradisi sirih pinang di Indonesia telah teliti oleh Maidilla Siska Putri (2014) yang melihat ekspresi seni melalui tari makan sirih, Diaspora Tualaka (2017), tradisi oko'mama (tempat menyimpan sirih pinang) dalam kajian ekolinguistik. Menguyah sirih sebagai salahsatu tradisi di India ditinjau (Toprani \& Patel, 2013) dari sudut pandang kesehatan. Riset mengenai simbol sirih pinang memiliki ruang yang sangat luas untuk diteliti lebih lanjut sebagai bagian dari tradisi ragam suku di Indonesia dan Asia maupun dari berbagai disiplin ilmu lainnya.

Penelitian pada tradisi Sirih Pinang pada Suku Atoni Pah Meto di wilayah Kefetoran Aplal, Timor Tengah Utara untuk menjawab pertanyaan penelitian mengenai Simbol dan makna sirih pinang sebagai hasil interaksi dalam kaitannya dengan perilaku komunikasi pada masyarakat. Secara umum, penelitian ini untuk menemukan makna di ruang sosial.

\section{Tinjauan Pustaka}

Pada mulanya makna itu tidak ada sebelum adanya interaksi. Untuk setiap makna dibutuhkan sebuah simbol untuk diinterpretasi bersama-sama dalam sebuah proses komunikasi. Setelah itu, sebuah benda atau sebuah 'lambang' menjadi simbol tertentu dan memiliki arti. Melalui tindakan interaksi berulang, individu sebagai aktor dalam kaitannya dengan kelompok sosial berbagi makna simbolik (Del Casino \& Thien, 2009)

Komunikasi adalah pertukaran simbol. Komunikasi akan menjadi efektif apabila komunikator dan komunikan memiliki persepsi yang sama terhadap simbol. Mulyana (2006:83-120) mengemukakan komunikasi sebagai proses simbolik. Simbol digunakan sebagai ekspresi pikiran, perasaan individu, kelompok budaya atau sebuah komunitas. Pengetahuan terhadap simbol-simbol akan menunjang efektifitas komunikasi. Dalam interaksionisme simbolik, tidak menyangkal keunikan; ini berkaitan langsung dengan bagaimana makna yang berbeda diadaptasi dan ditafsirkan melalui praktik sosial (Del Casino \& Thien, 2009)

Dengan menggunakan asumsi Mead, Asworth (2000:127) menjelaskan, bahwa simbol merupakan proses pikiran. Selaras dengan filsafat pragmatisme John Dewey yang memiliki pandangan, bahwa pikiran bukanlah benda atau sebuah struktur, melainkan sebuah proses yang melalui berbagai berbagai tahapan. Pikiran manusia ada sebagai akibat dari aktivitas dan kegiatan manusia itu sendiri. Simbol adalah produk dari pikiran. Komunikasi dalam teori interaksi simbolik adalah pertukaran simbol-simbol untuk diberikan makna. Pemaknaan atas simbol-simbol dalam sebuah budaya adalah hasil dari interaksi sosial kemudian diinterpretasikan bersama. Interaksionisme Simbolik adalah perspektif sosiologis yang berbeda yang menekankan sentralitas analitik dalam menyelidiki makna yang diberikan orang pada kegiatan mereka (Dennis \& Smith, 2015).

Teori interaksi simbolik yang dikembangkan oleh Blumer (1986:2) bersandar kepada tiga premis : Pertama, manusia bertindak terhadap sesuatu berdasarkan makna yang dimiliki benda-benda itu bagi mereka. Kedua, makna muncul karena adanya interaksi sosial seseorang dengan orang lain. Ketiga, makna dimodifikasi melalui proses interpretatif dalam keterlibatannya dengan benda-benda dan tanda-tanda yang digunakan. Selanjutnya Blumer menyampaikan, dalam interaksi simbolik, makna yang dimiliki benda-benda sangatlah penting (1986:15). Dalam sebuah penelitian antara simbol dan budaya, mengabaikan makna dari sebuah simbol 
budaya dipandang sebagai kerancuan dan juga pemalsuan perilaku masyarakat yang diteliti.

Teori interaksi simbolik mengakui prinsip makna sebagai pusat perilaku manusia. Bahasa memberikan makna bagi manusia melalui simbol. Simbol yang membedakan hubungan sosial manusia dari tingkat komunikasi hewan. Manusia memberi makna pada simbol dan mereka mengekspresikan halhal ini melalui bahasa. Karena itu, simbol membentuk dasar komunikasi(Aksan et al., 2009).

Seluruh bentuk-bentuk komunikasi adalah simbol-simbol yang bergantung kepada interaksi dan makna dari simbol-simbol tersebut. Dalam perilaku komunikasi manusia makna, bahasa dan pikiran memiliki peran penting.

\section{Metode Penelitian}

Secara metodologis, interaksi simbolik umumnya diselidiki melalui berbagai pendekatan kualitatif, seperti etnografi atau observasi partisipan (Del Casino \& Thien, 2009). Blumer menciptakan istilah interaksi simbolik dan menyarankan observasi partisipan sebagai metode yang disukai untuk mempelajari interaksi (Fontana, 2001). Dalam penelitian ini, peneliti menggunakan pendekatan kualitatif, dan melakukan observasi partisipan di wilayah Timor Tengah Utara.

Tiga orang Penatua Adat menjadi key informan dalam penelitian ini, dan selanjutnya penelitian dilakukan dengan cara observasi partisipan dalam kehidupan masyarakat Suku Atoni Pah Meto. Kriteria Penatua Adat dalam Suku Atoni Pah Meto tidak merujuk pada usia melainkan status sosial dalam komunitas. Penatua Adat dalam Suku Atoni Pah Meto adalah gudang ingatan sejarah dan pengetahuan yang bekenaan dengan tradisi serta mitos lokal (P.Richard Daschbach SVD, 1990:104). Penatua Adat memiliki posisi sebagai pemimpin dalam upacara-upacara ritual dan seorang pembuat keputusan hukum adat. Para Penatua Adat juga memiliki pengetahuan mendalam mengenai sirih pinang dan tradisi mengunyah sirih pinang, dan dalam konteks apa saja digunakan dan mengetahui nilai serta makna simbolik di balik tradisi ini. Sedangkan hidup dan bergaul dengan masyarakat sebagai objek penelitian, membantu untuk memahami bagaimana sirih pinang sebagai simbol dinterpretasi atau dimaknai dalam kehidupan keseharian mereka. Selain itu, pada kalangan masyarakat tradisional Suku Atoni Pah Meto dapat ditemukan makna-makna lainnya yang dapat diketahui melalui pengamatan dan perbincangan di antara mereka.

\section{Hasil Dan Pembahasan}

Saat akan memasuki wilayah penelitian di Miomaffo Barat, seorang Penatua Adat memberikan panduan, agar membawa sirih pinang dua kantong dan dua botol sopi. Ini dimaksudkan sebagai sopan santun budaya untuk melancarkan berkomunikasi, ujarnya. Yang pertama kali kami lakukan sebelum melakukan pembicaraan adalah mengunyah sirih pinang dan duduk melingkar bersama.

"Jika tidak bisa mengunyah sirih pinang atau tidak menyukai sirih pinang janganlah menampakkan ekspresi tidak suka atau menolak. Kamu harus mengambil bagian itu untuk disimpan, sekalipun tidak dimakan", ujar Penatua Adat.

Setelah itu, seluruh komunikasi kami menjadi lancar. Mereka menatap kami seakan teman lama dan keluarga. Di pertengahan pembicaraan, Para Penatua Adat minum sopi (minuman tradisional yang mengandung alkohol yang berasal dari air nira pohon lontar). Salah satu dari mereka berkata:

"Jika kami minum sopi, kami akan bicara apa saja dan sulit berhenti", ujarnya sambil tertawa.

Pada waktu lainnya, untuk mendapatkan data-data dalam penelitian dalam observasi partisipan, beberapa keluarga dikunjungi pada tempat berbeda, dan mereka senantiasa menyuguhkan sirih pinang dalam Oko' Mama (wadah sirih pinang). Sirih pinang selalu menjadi yang pertama harus diambil atau dikunyah sebelum masuk ke dalam pembicaraan. Mereka sangat malu yang luar biasa, jika di rumahnya tidak ada sirih pinang yang tersimpan di Oko' Mama.

Sirih pinang, kapur dan tembakau biasanya disuguhkan dalam tempat sirih pinang. Ada dua macam tempat sirih pinang, yaitu Oko Mama dan Tiba. Oko Mama adalah 
tempat sirih pinang yang terbuat dari anyaman daun lontar yang berbentuk kotak, dan biasanya digunakan oleh perempuan. Sedangkan Tiba adalah tempat sirih pinang yang terbuat dari bambu yang diukir. Namun, tempat untuk menyuguhkan sirih pinang kepada tamu di rumah biasanya adalah Oko' Mama. Baik Oko Mama maupun Tiba biasanya diberikan motif dan warna, dengan warna-warni yang menarik. Setiap lelaki dewasa di Suku Atoni Pah Meto, terutama di pedalaman, senantiasa akan menyelempangkan tas yang berisi sirih pinang saat berpergian, yang mereka sebut sebagai Alu Mama, sebagai simbol sopan santun budaya

Dalam tradisi sirih pinang keseluruhannya memiliki makna mendalam yang menyentuh lapisan-lapisan budaya yang tak nampak. Budaya ini lahir dari kehidupan Suku Atoni Pah Meto sebagai masyarakat kolektivis, hubungan sesama manusia mendapatkan perhatian utama dan mendapatkan prioritas dibandingkan dengan kehidupan pribadi. Sirih pinang adalah sebuah ekspresi batin, sebagai bentuk penerimaan, persahabatan dan kekeluargaan. Saat sirih pinang disuguhkan dan makan bersama-sama dalam Suku Atoni Pah Meto, melambangkan niat baik dan ketulusan hati, menerima satu dengan lainnya dengan hormat.

Dalam tradisi Suku Atoni Pah Meto, sirih pinang adalah simbol budaya yang dapat dibawa ke dalam konteks komunikasi antar pribadi, komunikasi intrabudaya, komunikasi ritual dan komunikasi politik. Pada kontekskonteks tersebut, sirih pinang memiliki nilai dan maknanya sendiri.

\subsection{Makna Sirih dan Pinang}

Sirih pinang dalam kehidupan masyarakat Suku Atoni Pah Meto memiliki makna sebagai simbol penghargaan tertinggi dalam interaksi antar manusia. Di sisi lain, Suku Atoni Pah Meto memiliki filosofi dan mitos yang berkaitan dengan sirih pinang yang tidak untuk dibuktikan secara logika karena sudah tertanam dalam sistem kepercayaan yang telah berlangsung selama berabad-abad. Generasi Suku Atoni Pah Meto dari waktu ke waktu menerimanya sebagai bagian dari tradisi di dalam kehidupan mereka. Namun demikian, tidak seluruh anggota suku kecanduan mengunyah sirih pinang dengan berbagai alasan.

\subsection{Makna Sirih Pinang dalam Komunikasi Antar Pribadi}

Dalam komunikasi antar pribadi, orang bertatap muka dan saling bertukar secara verbal dan non verbal satu dengan lainnya. Sirih pinang adalah pembuka komunikasi, sebagai isyarat, "Mari kita saling berbicara". Sirih pinang akan membangun keakraban, kekeluargaan dan rasa persahabatan, serta untuk menjaga hubungan baik. Mereka membuang ludah yang memerah bersama-sama di tanah atau di tempat di mana mereka pijak. Mereka berbagi kehidupan melalui simbol saat berinteraksi.

\subsection{Makna Sirih Pinang dalam Komunikasi Intrakultural \& Interkultural}

Sirih pinang adalah tentang rasa hormat. Sebagai sopan santun budaya dan penghargaan kepada sesama, bahwa mereka memiliki kedudukan yang sama, baik tamu maupun pribumi. Sirih pinang menjadi simbol bahwa kehadiran mereka diterima dengan hati yang tulus dan terbuka. Sirih pinang menjadi 'jembatan' komunikasi dan memberikan kepastian makna, sebuah rasa persahabatan dan kekeluargaan untuk menemukan kerjasama dan kegembiraan yang dibagi bersama dan berbagi cerita-cerita tentang kehidupan.

$$
\text { Dalam pandangan }
$$

tradisional,"meaning " sebagai pertambahan psikis yang dibawa orang untuk siapa benda itu memiliki makna. Arti sesuatu hanyalah ekspresi dari yang diberikan unsur-unsur psikologis yang dimainkan sehubungan dengan persepsi benda; dengan demikian orang berusaha menjelaskan arti sesuatu dengan mengisolasi unsur-unsur psikologis tertentu yang menambah atau mengurangi maknanya. (Blumer,1986:15).

\subsection{Makna Sirih Pinang dalam Komunikasi Ritual}

Sirih pinang menjadi penghubung antara manusia dengan leluhur. Mereka memberikan persembahan untuk leluhur yang berwujud arwah dalam upacara ritual adat, dan biasanya beserta makanan dan minuman lainnya. Bagi Suku Atoni Pah Meto, leluhur 
tidak pernah jauh dari mereka, mereka selalu ada dan menjadi pendoa-pendoa bagi mereka yang masih hidup. Doa-doa yang hidup akan diteruskan oleh arwah para leluhur kepada Tuhan Langit (Uis Neno) supaya diberikan berkat.

Dalam pernikahan, daun sirih yang dipakai di dalam upacara harus memiliki ciri tertentu. Sirih Pinang menjadi salah satu syarat penting terselenggaranya upacara adat pernikahan. Setiap upacara pernikahan dalam anggota Suku Atoni Pah Meto akan berkaitan dengan tradisi dan terhubung dengan leluhurleluhur mereka karena di dalamnya ada upacara peleburan nama marga perempuan kepada marga laki-laki, yang akan terhubung dengan identitas leluhur mereka pada sebuah tempat yang sakral dan suci yang mereka sebut sebagai Faotkanaf-Oekanaf.

Selain itu, pada setiap upacara-upacara adat yang melibatkan tua-tua adat, mereka akan mengunyah sirih pinang untuk mengukuhkan keputusan yang bersifat mengikat seluruh anggota suku. Mereka akan mengatakan bahwa keputusan-keputusan sosial lahir dari semangat ansaofmese-nekafmese (satu hati, satu jiwa). Dalam masyarakat tradisional Suku Atoni Pah Meto, keterikatan pada nilai-nilai budaya sangat kuat, di mana tidak ada pemisahan yang jelas antara yang religius dan yang profan. Setiap kegiatan dalam masyarakat adat, akan melibatkan pada Penatua Adat, karena mereka meyakini sebagai kegiatan sosial religius.

3.1.5. Makna Sirih Pinang dalam Komunikasi Politik

Persaingan politik antara calon legislatif dalam pemilihan umum untuk menjadi angggota parlemen di tingkat daerah dan tingkat pusat telah membuat iklim politik menjadi tidak sehat. Demikian pula, pemilihan kepala-kepala daerah yang dipilih langsung oleh rakyat membuat persaingan antara kandidat mencari perhatian untuk merebut hati calon konsituen. Untuk mendapatkan pengakuan pada masyarakat, para calon anggota parlemen dan calon kepala daerah mendatangi para Penatua Adat untuk memperoleh dukungan. Kekuatan pengaruh Penatua Adat sangat besar dalam masyarakat tradisional untuk memengaruhi anggota klan atau anggota suku. Berbagai upaya mereka lakukan. Sirih pinang menjadi alat lobby kepada untuk membangun komunikasi.

Masyarakat tradisional memiliki kepercayaan kepada para Penatua Adat yang sangat besar. Bilamana komunikasi politik sirih pinang dapat menembus mereka, maka calon anggota legislatif dan calon kepala daerah akan memiliki peluang besar mendapatkan dukungan. Komunikasi politik sirih pinang adalah tentang pergeseran makna. Simbol Sirih Pinang yang luhur dan mulia dan telah melekat dalam kehidupan masyarakat menjadi terdegradasi, di mana simbol kemudian memiliki makna yang berbeda, menjadi intrik dan perhitungan kalkulasi politik.

Penelitian mengenai simbol dan makna sirih pinang sebagai hasil interaksi dalam kaitannya dengan perilaku komunikasi pada masyarakat akhirnya dapat diketahui, bahwa Sirih pinang memiliki 'tugas' simbol yang sangat kuat dalam kehidupan Suku Atoni Pah Meto. Seluruh tindakan-tindakan sosial masyarakat tradisional ini, tidak bisa dilepaskan dari Sirih pinang. Sirih pinang menjadi bahasa simbol untuk dipertukarkan dan dimaknai bersama-sama dalam interaksi sosial mereka yang telah berlangsung selama berabad-abad, dan mereka mewariskan simbol dan makna sirih pinang dari generasi ke generasi. Sirih pinang menjadi simbol yang kokoh dalam kehidupan Suku Atoni Pah Meto karena tersambung dengan praktik-praktik ritual adat yang bersumber dari nilai-nilai kepercayaan lokal atau agama asli leluhur mereka.

Simbol akan memiliki makna yang kuat dan melekat bilamana dihidupkan dan dipertukarkan secara konsisten dalam interaksi sosial di mana di dalamnya terdapat spirit religiulitas dan masyarakat menerimanya sebagai sesuatu yang tak perlu dipertanyakan ulang.

\section{Simpulan Dan Saran}

Sebagai masyarakat tradisional yang masih terikat erat dengan tradisi dan struktur budaya lokal yang sangat kuat, Suku Atoni Pah Meto tidak mudah melepaskan simbolsimbol budaya seperti sirih pinang yang telah menyatu di dalam kehidupan mereka. Sirih pinang adalah sebuah media yang mendasar 
bagi terbangunnya seluruh bentuk-bentuk komunikasi yang efektif dan interaksi sosial dalam Suku Atoni Pah Meto saat mengunyah bersama-sama.

Kekuatan tradisi yang bersumber dari nilai-nilai budaya dan agama asli leluhur Suku Atoni Pah Meto, di mana Penatua Adat diyakini sebagai perpanjangan suara dari arwah-arwah leluhur untuk membaca tanda-tanda pada upacara-upacara adat, membuat sirih pinang yang menjadi salah satu kelengkapan dalam setiap upacara memiliki simbol yang sangat kuat, dan makna yang melekat.

Sebagai masyarakat kolektivis dan berada di pedalaman di mana interaksi sosial masih sangat baik dan komunikasi tatap muka memiliki ruang yang lebih banyak, pertukaran simbol sirih pinang memiliki daya persuasi yang lebih intim, makna akan lebih mudah dihidupi bersama yang menyentuh ruang kesadaran individu dan masyarakat.

Mengingat ceruk pasar yang sangat luas, sangat baik apabila digalakan pengembangan pertanian sirih pinang, agar mencukupi wilayah Timor Barat, atau mungkin Timor ke Timor Leste untuk diekspor untuk menambah devisa negara. Mengingat mereka memiliki tradisi Sirih Pinang, karena pada dasarnya seluruh penduduk Pulau Timor itu memiliki banyak persamaan suku dan tradisi. Selama ini, sirih pinang masih ada yang didatangkan dari pulau-pulau lainnya, bahkan dari Pulau Jawa. Budidaya sirih pinang secara massal di samping meningkatkan pendapatan masyarakat untuk memakmurkan ekonomi keluarga, juga memberikan dampak ekologis sebagai penghijauan di Tanah Timor yang kering dan gersang.

\section{Daftar Pustaka}

Aksan, N., Kısac, B., Aydın, M., \& Demirbuken, S. (2009). Symbolic interaction theory. Procedia - Social and Behavioral Sciences, 1(1), 902-904. https://doi.org/10.1016/J.SBSPRO.2009. 01.160 .

Blumer, Herbert. 1986. Symbolic Interactionism Perspective and Method. University of California Press.
Del Casino, V. J., \& Thien, D. (2009). Symbolic Interactionism. International Encyclopedia of Human Geography, 132-137. https://doi.org/10.1016/B978008044910-4.00752-5.

Dennis, A., \& Smith, G. (2015). Interactionism, Symbolic. International Encyclopedia of the Social \& Behavioral Sciences, 352-356. https://doi.org/10.1016/B978-0-08097086-8.32079-7.

Fontana, A. (2001). Symbolic Interaction: Methodology. International Encyclopedia of the Social \& Behavioral Sciences, 15347-15350. https://doi.org/10.1016/B0-08-0430767/00772-5.

Mulyana, Deddy. 2006. Ilmu Komunikasi Suatu Pengantar. PT Remaja Rosda Karya.

Nordholt, Schulte H.G. 1971. The Political System of The Atoni of Timor. The Hague-Martinus Nijhoff.

Norton, S. A. (1998). Betel: Consumption and consequences. Journal of the American Academy of Dermatology, 38(1), 81-88. https://doi.org/10.1016/S01909622(98)70543-2.

P.Richard Daschbach SVD. "Batu Karang di Bebu". dalam Agenda Budaya Pulau Timor (P. Gregor Neonbasu SVD.eds). 1990. Komisi Komunikasi Sosial Propinsi SVD di Kupang.

Putri, Maidilla Siska, et.al. 2014. Makna Sirih dalam Tari Makan Sirih di Tanjung Batu Kecamatan Kundur Kabupaten Karimun Kepulauan Riau. Jurnal Sendra Tasik. Vol (2) No. 2.

Toprani, R., \& Patel, D. (2013). Betel leaf: Revisiting the benefits of an ancient Indian herb. South Asian Journal of Cancer, 2(3), 140-141. https://doi.org/10.4103/2278- 
330X.114120.

Tualaka, Diaspora.2018. Degradasi Fungsi Makna dan Nilai Budaya Oko'Mama Pada Komunitas Tutur Uab Meto. Litera : Jurnal Litera Bahasa dan Sastra. Vol (4): 1 .
White, R. E., Carlson, S. M., \& David Zelazo, P. (2019). Symbolic Thought. Reference Module in Neuroscience and Biobehavioral Psychology. https://doi.org/10.1016/B978-0-12809324-5.23266-5 